\title{
The mechanism of oxythiamine-induced collagen biosynthesis in cultured fibroblasts
}

\author{
Lukasz Szoka $\cdot$ Ewa Karna $\cdot$ Jerzy Palka
}

Received: 28 August 2014/ Accepted: 17 January 2015/Published online: 28 January 2015

(C) The Author(s) 2015. This article is published with open access at Springerlink.com

\begin{abstract}
The oxythiamine (OXY) is antivitamin of thiamine. The finding that OXY increases the cytoplasmic concentration of pyruvate, known to enhance collagen biosynthesis, led us to investigate the mechanism of this antivitamin action on collagen biosynthesis in cultured human skin fibroblasts. Confluent fibroblasts were treated with micromolar concentrations $(30-1,000 \mu \mathrm{M})$ of $\mathrm{OXY}$ for 24 and $48 \mathrm{~h}$. It was found that OXY-dependent increase in collagen biosynthesis was accompanied by parallel increase in prolidase activity and level, compared to untreated cells. Since phosphoenolpyruvate (PEP) is known as an inhibitor of prolidase- the enzyme that plays important role in collagen biosynthesis, the mechanism of pyruvate interconversion was considered as a regulatory switch in collagen biosynthesis. In fact, 3-MPA, specific inhibitor of phosphoenolpyruvate carboxykinase (PEPCK), contributed to up-regulation of prolidase activity, suggesting that down-regulation of PEP formation is an underlying mechanism. Since collagen biosynthesis and prolidase activity are regulated by signal induced by activated $\alpha_{2} \beta_{1}$ integrin receptor as well as insulin-like growth factor-I receptor (IGF-IR), the expression of these receptors was measured by Western immunoblot analysis. The exposure of the cells to OXY contributed to decrease in IGF-IR, $\alpha_{2} \beta_{1}$ integrin receptor, pERK1/2, and NF- $\kappa \mathrm{B}$ p65 expressions. It was accompanied by increase in total ERK1/2 expression and induction of phosphorylation of Akt protein. The data suggest that OXY-dependent increase of collagen biosynthesis in cultured human skin fibroblasts results from activation of prolidase activity and level, induction in pAkt
\end{abstract}

L. Szoka $\cdot$ E. Karna $\cdot$ J. Palka $(\bowtie)$

Department of Medicinal Chemistry, Medical University of

Bialystok, Mickiewicza 2 D, 15-222 Bialystok, Poland

e-mail: pal@umb.edu.pl expression and down-regulation of pERK1/2 and NF- $\kappa \mathrm{B}$ $\mathrm{p} 65$, the known inhibitor of collagen gene expression.

Keywords Oxythiamine $\cdot$ Collagen biosynthesis . Prolidase $\cdot$ ERK1/2 $\cdot$ Akt $\cdot$ NF- $\kappa$ B p65

\section{Introduction}

Oxythiamine $(\mathrm{OXY})$ is antivitamin of thiamine. It interferes with the enzymes of thiamine pyrophosphate-dependent pathways and can inhibit conversion of glucose into pentose phosphate that is necessary for the synthesis of nucleotides and metabolism of amino acids [1]. OXY increases the amount of pyruvate by inhibition of pyruvate decarboxylase [2]. Pyruvate has a key position in several metabolic pathways such as glycolysis and gluconeogenesis. Inhibition of pyruvate decarboxylase, which is part of the pyruvate dehydrogenase complex may interfere with the course of the oxidative decarboxylation of pyruvate. The result of this phenomenon is accumulation of pyruvate in the cell.

It was documented that pyruvate enhances collagen biosynthesis in slices of liver of cirrhotic rats [3]. The role of OXY in collagen biosynthesis, however, is not known.

It was also found that in the presence of oxythiamine the activity of cytosolic enzymes, transketolase, and pyruvate decarboxylase was down and up-regulated, dependently on time of incubation. At least in case of pyruvate decarboxylase, increase in the enzyme activity was followed by an increase in the amount of the enzyme protein [4], suggesting transcriptional regulation.

Since PEP is known as an inhibitor of prolidase-the enzyme that play important role in collagen biosynthesis, the mechanism of pyruvate interconversion may represent regulatory switch in collagen biosynthesis. 
Prolidase [EC 3.4.13.9] is a cytosolic enzyme that catalyzes the hydrolysis of imidodipeptides with C-terminal proline or hydroxyproline [5-7]. The enzyme plays an important role in the recycling of proline from imidodipeptides (derived from degradation products of collagen) for collagen re-synthesis [8] and cell growth [9]. The efficiency of recycling of proline was found to be about $90 \%$ [10]. It is evident that an absence of prolidase severely impedes the recycling of collagen proline. Some clinical symptoms related to collagen deficit can be attributed to prolidase deficiency [11]. On the other hand, increased activity of liver prolidase was found during fibrotic process [12]. It suggests that the enzyme activity (despite the collagen gene expression) may be a step-limiting factor in regulation of collagen biosynthesis. It has been supported by several studies [13-16].

Prolidase activity is stimulated through a signal mediated by collagen- $\beta_{1}$ integrin receptor interaction $[17,18]$. On the other hand, prolidase activity "in vitro" is inhibited by a strong, competitive inhibitor, PEP, that arises from pyruvate [19, 20].

Another factor that strongly stimulates collagen biosynthesis is insulin-like growth factor-I (IGF-I), acting predominantly through the IGF-I receptor [21, 22]. The effects of IGF-I include induction of collagen gene expression [23], up-regulation of prolidase activity [24], stimulation of mitotic division and prevention of apoptosis [21]. Some of these activities are regulated through NF- $\kappa \mathrm{B}$, the known inhibitor of collagen gene expression [25].

In this study, we examined the effect of OXY on cell viability, collagen biosynthesis, prolidase activity and level, expression of $\alpha_{2} \beta_{1}$ integrin, IGF-I receptor, MAP kinases $\left(\mathrm{ERK}_{1}, \mathrm{ERK}_{2}\right)$, Akt protein, and the transcription factor-NF- $\kappa$ B p65 in human dermal fibroblasts.

\section{Materials and methods}

Alkaline phosphatase-labeled anti-mouse IgG and anti-rabbit IgG antibodies, bacterial collagenase, 3-(4,5-di-methylthiazole-2-yl)-2,5-diphenyltetrazolium bromide (MTT), Fast BCIP/NBT reagent, L-glycyl-proline, L-proline, monoclonal (mouse) anti-IGF-IR, anti-pERK1/2 and polyclonal (rabbit) anti- $\beta$-actin antibodies, sodium pyruvate, and oxythiamine, were provided by Sigma Corp., USA., as were most other chemicals and buffers used. Dulbecco's minimal essential medium (DMEM) and fetal bovine serum (FBS) used in cell culture were products of Gibco, USA. Glutamine, penicillin, and streptomycin were obtained from Quality Biological Inc., USA. Nitrocellulose membrane $(0.2 \mu \mathrm{m})$, sodium dodecyl sulphate (SDS), polyacrylamide, molecular weight standards, and Coomassie Brilliant Blue R-250 were received from Bio-Rad Laboratories, USA.
$\mathrm{L}-5\left[{ }^{3} \mathrm{H}\right]$ proline $(28 \mathrm{Ci} / \mathrm{mmol})$ was purchased from Amersham, UK. Monoclonal (mouse) anti- $\beta_{1}$ and polyclonal (rabbit) anti- $\alpha_{2}$-integrin and anti-NFKB p65 antibodies were the products of Santa Cruz Biotechnology Inc., USA. Polyclonal (rabbit) anti-ERK1/2 and monoclonal (rabbit) antipAkt antibodies were the products of Cell Signaling Inc., USA. Polyclonal anti-human prolidase antibody was donated by Dr. James Phang (NCI-Frederick Cancer Research and Development Center, Frederick, MD, USA). 3-mercaptopicolinic acid (3-MPA) was purchased from Applichem GmbH, Germany.

Tissue culture

All studies were performed on normal human skin fibroblasts (CRL-1474), that were purchased from American Type Culture Collection, Manassas, VA, USA. The cells were maintained in DMEM supplemented with $10 \%$ fetal bovine serum (FBS), $2 \mathrm{mmol} / \mathrm{l}$ glutamine, $50 \mathrm{U} / \mathrm{ml}$ penicillin, and $50 \mu \mathrm{g} / \mathrm{ml}$ streptomycin at $37{ }^{\circ} \mathrm{C}$ in a $5 \% \mathrm{CO}_{2}$ incubator. Cells were counted in hemocytometer and cultured at $1 \times 10^{5}$ cells per well in $2 \mathrm{ml}$ of growth medium in 6-well plates (Costar). Cells reached confluence at day 6 and in most cases such cells were used for assays. Cells were used in the 8th to 14th passages.

\section{Cell viability assay}

The assay was performed according to the method of Carmichael [26] using 3-(4,5-di-methylthiazole-2-yl)-2,5diphenyltetrazolium bromide (MTT). The cells were cultured for 24 and $48 \mathrm{~h}$ with various concentrations of $\mathrm{OXY}$ in six-well plates, washed three times with PBS, and then incubated for $4 \mathrm{~h}$ in $1 \mathrm{ml}$ of MTT solution $(0.5 \mathrm{mg} / \mathrm{ml}$ of PBS) at $37{ }^{\circ} \mathrm{C}$. The medium was removed, and $1 \mathrm{ml}$ of $0.1 \mathrm{~mol} / \mathrm{H} \mathrm{HCl}$ in absolute isopropanol was added to attached cells. Absorbance of converted dye in living cells was measured at a wavelength of $570 \mathrm{~nm}$. OXY-treated cells viability was calculated as a percent of control cells.

Determination of prolidase activity

The activity of prolidase was determined according to the method of Myara [27]. Protein concentration was measured by the method of Lowry [28]. Enzyme activity was reported as nanomoles of proline released from synthetic substrate, during 1 min per milligram of supernatant protein of cell homogenate.

Collagen production

Incorporation of radioactive precursor into proteins was measured after labeling of confluent cells (cultured in growth 
medium with $\mathrm{OXY}$ ) for the last $24 \mathrm{~h}$ with $5\left[{ }^{3} \mathrm{H}\right]$ proline $(5 \mu \mathrm{Ci} / \mathrm{ml}, 28 \mathrm{Ci} / \mathrm{mM})$ as described previously [29]. Incorporation of tracer into collagen was determined by digesting proteins with purified Clostridium histolyticum collagenase, according to the method of Peterkofsky [30]. Results are shown as combined values for cell plus medium fractions.

\section{SDS-PAGE}

Slab SDS/PAGE was used according to the method of Laemmli [31], using $10 \%$ SDS-polyacrylamide gel.

\section{Western Immunoblot Analysis}

After SDS-PAGE, the gels were allowed to equilibrate for $5 \mathrm{~min}$ in $25 \mathrm{mmol} / \mathrm{l}$ Tris, $0.2 \mathrm{~mol} / \mathrm{l}$ glycine in $20 \%$ (v/v) methanol. The protein was transferred to $0.2 \mu \mathrm{m}$ pore-sized nitrocellulose at $100 \mathrm{~mA}$ for $1 \mathrm{~h}$ using a LKB 2117 Multiphor II electrophoresis unit. The nitrocellulose was incubated with monoclonal anti- $\beta_{1}$ and polyclonal anti- $\alpha_{2}-$ integrin antibodies at concentration 1:1,000; polyclonal antibodies against NFKB p65, ERK1/2, and $\beta$-actin at concentration 1:3,000; polyclonal antibody against prolidase at concentration 1:5,000; monoclonal anti-IGF-IR, pERK1/2 and pAkt antibodies at concentration 1:1,000 in 5\% dried milk in TBS-T $(20 \mathrm{mmol} / \mathrm{l}$ Tris-HCl buffer, $\mathrm{pH} 7.4$, containing $150 \mathrm{mmol} / \mathrm{l} \mathrm{NaCl}$ and $0.05 \%$ Tween 20) for $1 \mathrm{~h}$. In order to analyze $\beta_{1}$ integrin subunit, IGF-IR, and pERK1/ 2 second antibody, alkaline phosphatase-conjugated antimouse IgG (whole molecule) was added at concentration 1:7,500 in TBS-T; in order to analyze prolidase, $\alpha_{2}$-integrin subunit, ERK1/2, pAkt, NFkB p65, and $\beta$-actin second antibody, alkaline phosphatase-conjugated anti-rabbit $\operatorname{IgG}$ (whole molecule) was added at concentration 1:5,000 in TBS-T and incubated for $30 \mathrm{~min}$ slowly shaking. Then nitrocellulose was washed with TBS-T $(5 \times 5 \mathrm{~min})$ and submitted to Sigma-Fast BCIP/NBT reagent. The intensity of the bands was quantified by densitometric analysis.

\section{Statistical Analysis}

In all experiments, the mean values for three independent experiments done in duplicates \pm standard deviation (SD) were calculated. The results were submitted to statistical analysis using the Student's $t$ test, accepting $P<0.01$ as significant.

\section{Results}

Studies were performed on confluent fibroblasts, since collagen synthesis, prolidase activity as well as IGF-IR expression depend on cell density [32, 33].
Since oxythiamine (OXY) was found to inhibit proliferation of tumor cells [34-36], the cytotoxicity assay for different doses of OXY in cultured human fibroblasts was performed. Cell viability was measured by the method of Carmichael et al. [26] using tetrazolium salt. The viability of OXY-treated fibroblasts is presented in Fig. 1a. OXY at studied concentrations did not influence the viability of the cells at 24 and $48 \mathrm{~h}$ incubation.

Collagen biosynthesis and prolidase activity were measured in confluent human dermal fibroblasts that have been treated with $30,100,300$, and $1,000 \mu \mathrm{M}$ of OXY. As can be seen in Fig. 1b, 24 and $48 \mathrm{~h}$ incubation of confluent fibroblasts in the medium containing $10 \%$ of FBS and different concentrations of OXY contributed to increase in collagen biosynthesis in a dose-dependent manner. $1,000 \mu \mathrm{M}$ OXY-induced increase in collagen biosynthesis by about $36 \%$ of control, after $24 \mathrm{~h}$ incubation and by about $14 \%$ of control after $48 \mathrm{~h}$ (Fig. 1b).

The mechanism of increase in collagen biosynthesis in OXY-treated cells may be due to the accumulation of pyruvate in the cell $[2,3]$. This led us to investigate the influence of pyruvate on this process. Unexpectedly, we found that an addition of different concentrations of pyruvate $(1,3,10,20 \mathrm{mM})$ contributed to reduce in collagen biosynthesis. At concentration of $20 \mathrm{mM}$, pyruvateinduced decrease in collagen biosynthesis to about $50 \%$ of control, after $24 \mathrm{~h}$ incubation (Fig. 1c).

To explain the mechanism of OXY-dependent increase in collagen biosynthesis, we considered prolidase as a target enzyme. Increase in collagen biosynthesis in OXY-treated cells was accompanied by increase in prolidase activity by about 57 and $14 \%$ after $24 \mathrm{~h}$ and $48 \mathrm{~h}$ incubation, respectively, compared to control (Fig. 2a). An increase in prolidase activity was accompanied by increase in the level of the enzyme protein, by about 141 and $41 \%$ after 24 and $48 \mathrm{~h}$ incubation, respectively, compared to control, as shown by Western immunoblot analysis (Fig. 2b, c).

The data show that OXY increases collagen biosynthesis in skin fibroblasts and suggest that an increase may result from stimulation of prolidase activity and expression.

We considered whether pyruvate or PEP is involved in OXY-dependent regulation of collagen biosynthesis. 3-MPA is an inhibitor of phosphoenolpyruvate carboxykinase (PEPCK). The enzyme is responsible for the conversion of oxaloacetate to PEP. We decided to check if inhibition of PEP formation can cause up-regulation of collagen biosynthesis and prolidase activity. In previous studies, we found that PEP down-regulate $\beta_{1}$ integrin and IGF-I receptors signaling providing mechanism for inhibition of collagen biosynthesis in fibroblast. Moreover, we found that there is no direct correlation between collagen biosynthesis and prolidase activity and the enzyme level [19]. 
Fig. 1 Viability a of confluent human skin fibroblasts incubated for 24 and $48 \mathrm{~h}$ with different concentrations of oxythiamine (OXY). The mean values \pm SD from three independent experiments done in duplicates are presented. ${ }^{*} P \leq 0.01$. Collagen biosynthesis measured as $5\left[{ }^{3} \mathrm{H}\right]$ proline incorporation into proteins susceptible to the action of bacterial collagenase in fibroblasts treated for 24 and $48 \mathrm{~h}$ with different concentrations of (OXY) (b) and sodium pyruvate $(\mathbf{c})$. The results present the mean values from 6 assays $\pm \mathrm{SD} * P \leq 0.01$
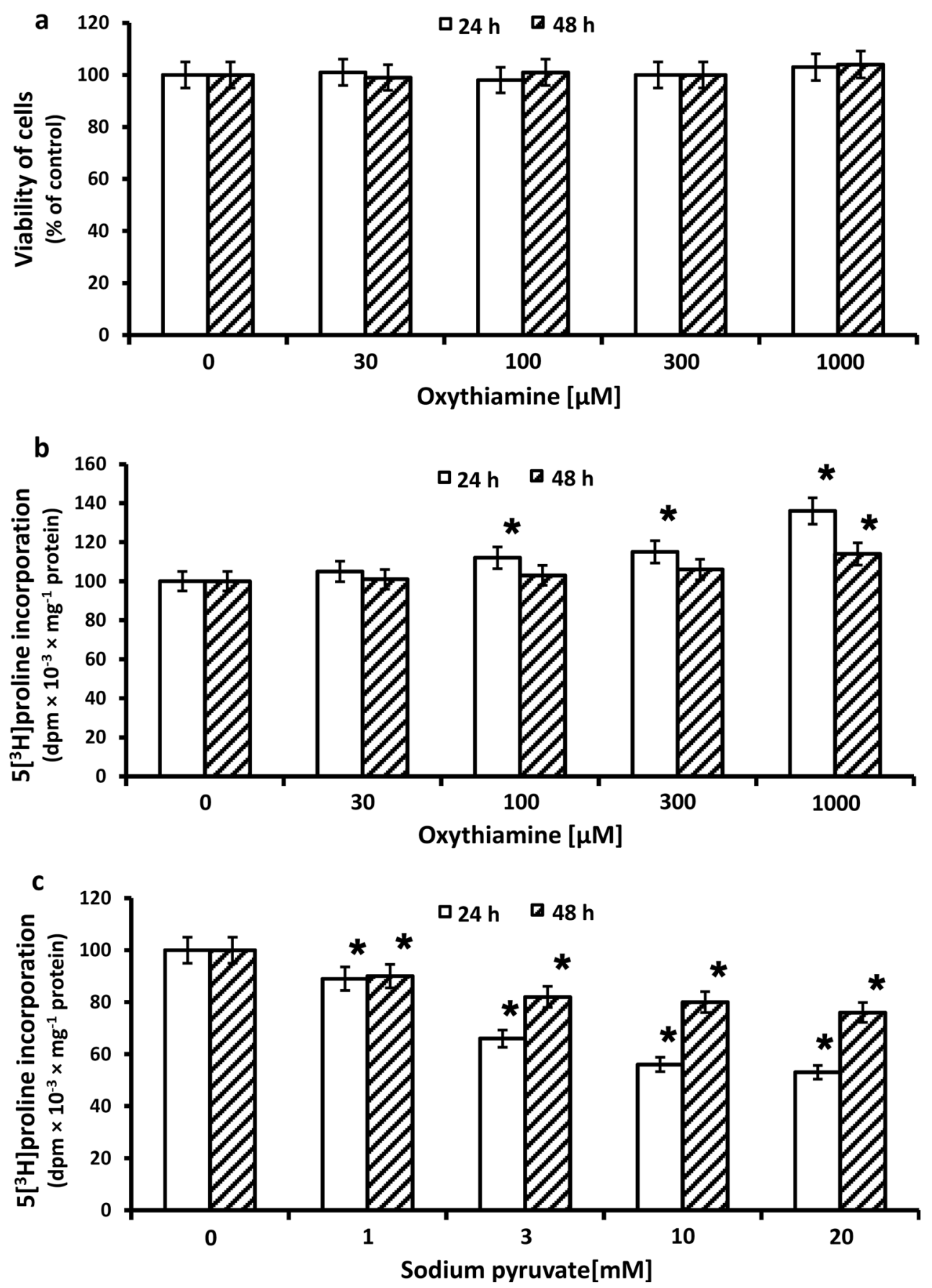

Therefore, the question was addressed whether an inhibitor of PEPCK, 3-mercaptopicolinate (3-MPA) affects oxythiamine-induced prolidase activity. As described previously, prolidase activity is stimulated by serum-derived growth factors [37]. Therefore, activity of this enzyme was measured in confluent fibroblasts, cultured for 1,6 , and $24 \mathrm{~h}$ in the medium containing $0.1 \%$ of fetal bovine serum (FBS), $1 \mathrm{mM}$ of 3-MPA, and different concentrations of OXY. The results were compared to the cells cultured for $1 \mathrm{~h}, 6 \mathrm{~h}$, and $24 \mathrm{~h}$ in the medium containing $10 \%$ FBS, 1 mM 3-MPA, and OXY.
As can be seen in Fig. 3a and c, 1 and $24 \mathrm{~h}$ incubation of fibroblasts in the medium containing $0.1 \% \mathrm{FBS}$ and $1 \mathrm{mM}$ OXY-induced prolidase activity, by about 40 and $30 \%$, respectively. However, $6 \mathrm{~h}$ incubation under the same conditions contributed to decrease in prolidase activity to $70 \%$ of control (Fig. 3b). The mechanism of this phenomenon may involve PEP accumulation that inhibits prolidase activity and collagen biosynthesis.

An addition of $1 \mathrm{mM}$ of 3-MPA under the same conditions contributed to increase in prolidase activity by 
Fig. 2 Prolidase activity a in confluent human skin fibroblasts incubated in the medium containing $10 \%$ FBS and different concentrations of OXY. The results present the mean values from 6 assays $\pm \mathrm{SD} * P \leq 0.01$. Western blot analysis for prolidase in fibroblasts incubated $24 \mathrm{~h} \mathrm{(b)}$ and $48 \mathrm{~h}$ (c) with different concentrations of OXY. The mean values of six pooled cell homogenate extracts from six separate experiments are presented. The intensity of the bands was quantified by densitometric analysis.

Densitometry was done with BioSpectrum Imaging System and presented as arbitrary units above the bands. $20 \mu \mathrm{g}$ of supernatant protein was run in each lane for prolidase and $\beta$ actin. The expression of $\beta$-actin served as a control for protein loading (d)

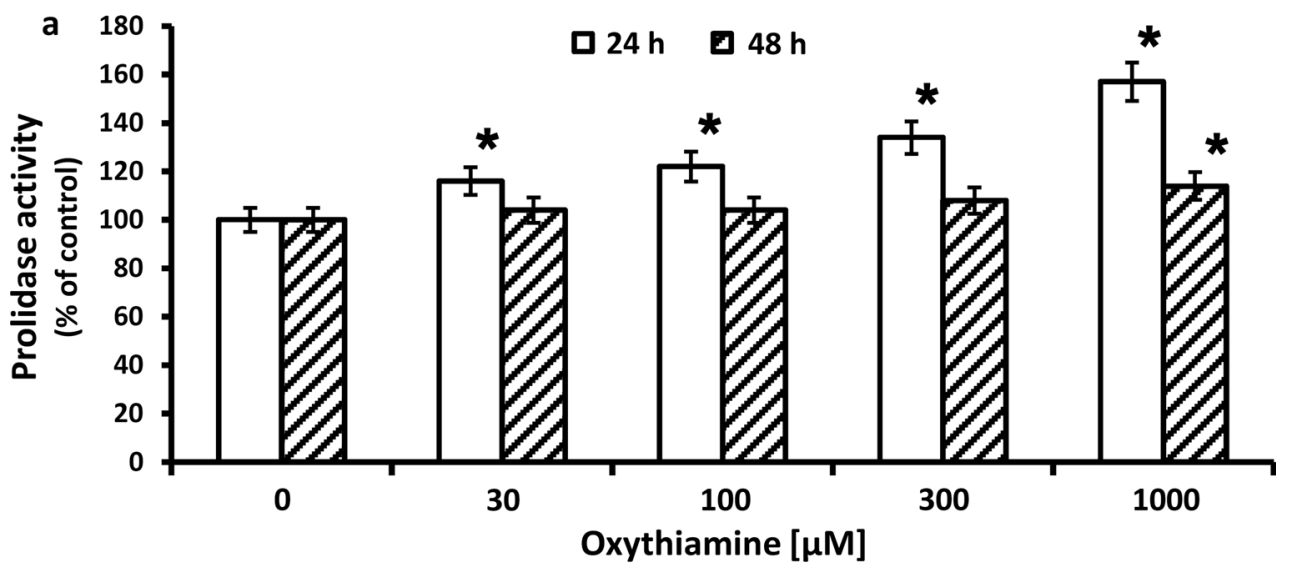

b

$56 \mathrm{kDa}$

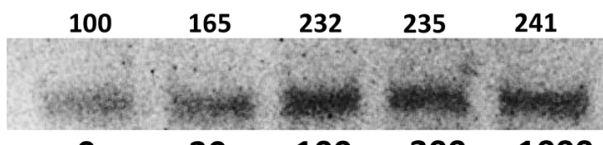

prolidase

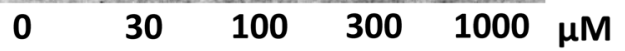

C

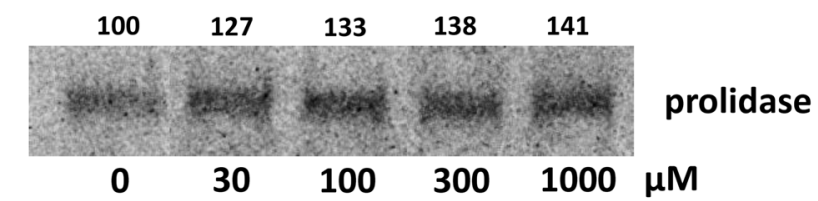

d

46 kDa

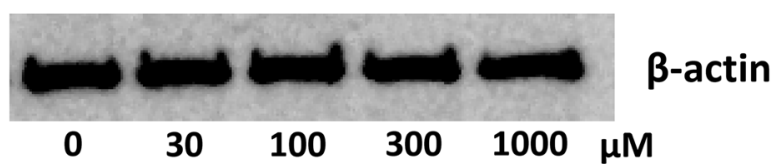

about 86 and $48 \%$ at 1 and $6 \mathrm{~h}$ incubation, and had no effect on prolidase activity after $24 \mathrm{~h}$ incubation. It may suggest that decreased activity of PEPCK contributes to suppression of PEP production (competitive inhibitor of prolidase activity) [20] and may be responsible for increase in the enzyme activity in first $6 \mathrm{~h}$ of incubation (Fig. 5, graphical abstract).

As can be seen in Fig. 3a and c, 1 and $24 \mathrm{~h}$ incubation of fibroblasts in the medium containing $10 \%$ FBS and $1 \mathrm{mM}$ OXY-induced prolidase activity, by about 55 and $27 \%$ of control, respectively. After $6 \mathrm{~h}$ incubation, 100, 300, and $1,000 \mu \mathrm{M}$ OXY increased prolidase activity by about 155 , 63 , and $13 \%$ of control, respectively (Fig. 3b).

An addition of $1 \mathrm{mM}$ of 3-MPA under the same conditions had small effect on prolidase activity after 1 and $6 \mathrm{~h}$ of incubation (increase by 8 and $5 \%$ of control values, Fig. 3a, b) and contributed to increase in enzyme activity by about $22 \%$ after $24 \mathrm{~h}$ incubation. In such conditions, we observed that PEPCK decreased prolidase activity (increased by OXY) after 1, 6, and $24 \mathrm{~h}$ incubation. It suggests that decreased activity of PEPCK contributes to suppression of PEP production (competitive inhibitor of prolidase activity) [20] and is responsible for slight increase in the enzyme activity (Fig. 5, graphical abstract).

Collagen biosynthesis and prolidase activity were previously shown to be regulated due to the signal induced by activated $\alpha_{2} \beta_{1}$ integrin receptor [17] as well as IGF-IR [12, 24]. Therefore, the expression of $\alpha_{2} \beta_{1}$ integrin receptor (receptor for type I collagen) and IGF-IR was measured by Western immunoblot analysis. As can be seen in Fig. 4a, 24 and $48 \mathrm{~h}$ treatment of fibroblasts with 30, 100, 300 and $1,000 \mu \mathrm{M}$ of OXY contributed to a distinct decrease in the expression of $\alpha_{2}$ integrin subunit to about $94,81,79$, and $46 \%$ respectively, at $24 \mathrm{~h}$, and to about $84,75,72$, and $67 \%$, respectively, at $48 \mathrm{~h}$, compared to the control cells. 24 and $48 \mathrm{~h}$ treatment of fibroblasts with $1,000 \mu \mathrm{M}$ of OXY reduced expression of $\beta_{1}$ integrin subunit to about 79 and $85 \%$, respectively, compared to the control (Fig. 4b). As shown in Fig. 4c, IGF-I receptor expression was decreased for 1,000 $\mu \mathrm{M}$ OXY-treated cells to about 76 and $82 \%$ at 24 and $48 \mathrm{~h}$ incubation, respectively, compared to the control cells. We found that the highest concentration of OXY decreases expression of phosphorylated ERK1/2 to about 64 and $81 \%$ at 24 and $48 \mathrm{~h}$ incubation, respectively 
Fig. 3 Prolidase activity in confluent human skin fibroblasts incubated for $1 \mathrm{~h} \mathrm{(a),} 6 \mathrm{~h}$

(b) and $24 \mathrm{~h} \mathrm{(c)} \mathrm{in} \mathrm{the} \mathrm{medium}$ containing $0.1 \%$ FBS or $10 \%$ FBS and $1 \mathrm{mM}$ of

3-mercaptopicolinate (3-MPA), and different concentrations of OXY. The results present the mean values from 6 assays $\pm \mathrm{SD} * P \leq 0.01$
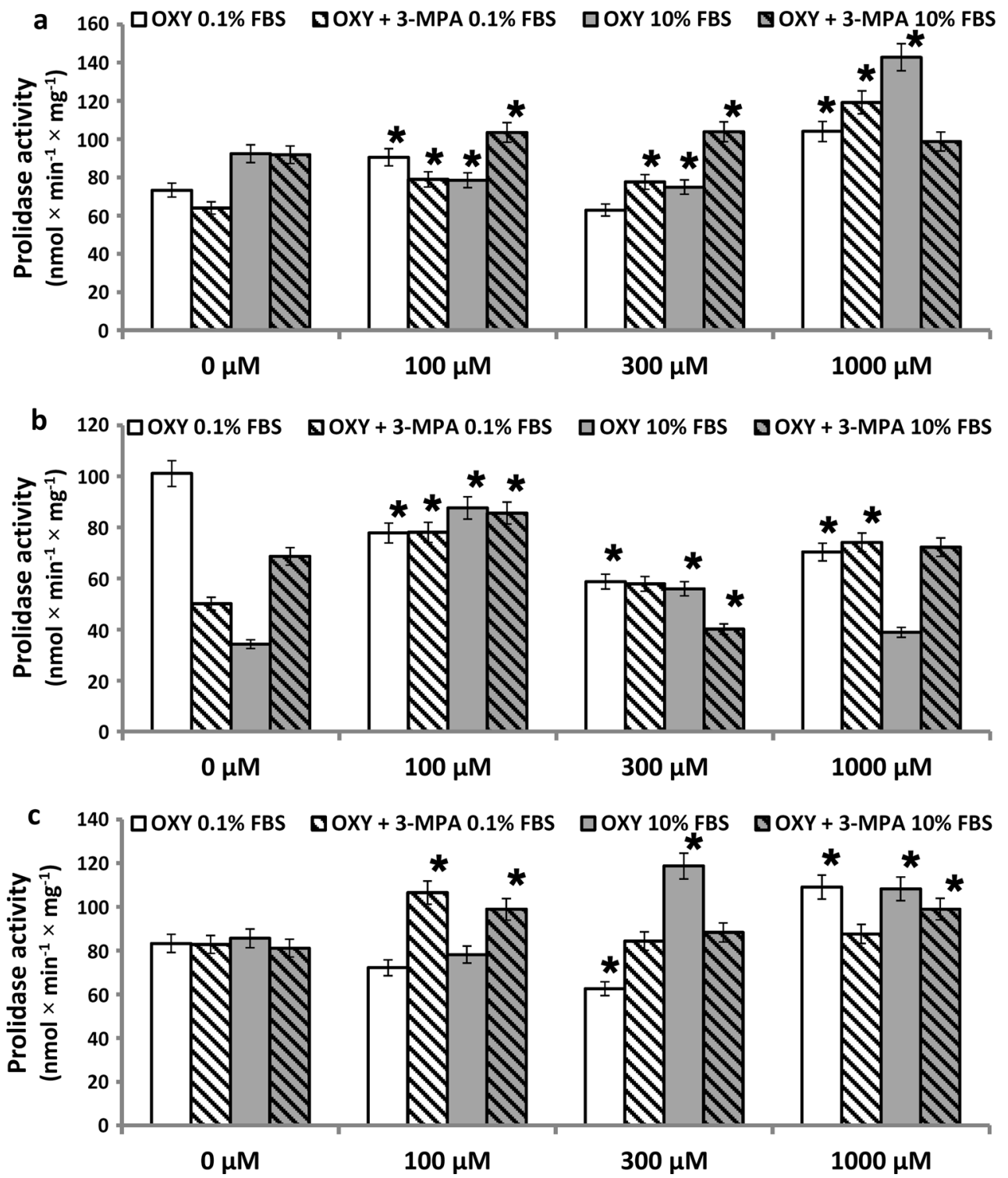

(Fig. 4d) and stimulates expression of total ERK1/2 by about $14 \%$ at $24 \mathrm{~h}$ and by about $36 \%$ at $48 \mathrm{~h}$, compared with control (Fig. 4e). Simultaneously, 1,000 $\mu \mathrm{M}$ of OXYdependent stimulation of total ERK1/2 expressions (Fig. 4e) was accompanied by similar induction of phosphorylation of Akt by about 19 and $20 \%$ at 24 and $48 \mathrm{~h}$ (Fig. 4f), suggesting that in the experimental conditions, ERK1/2 and Akt proteins represent signaling molecules that respond to OXY action.

On the other hand, we have found that in $24 \mathrm{~h} \mathrm{OXY}$-treated cells there is decrease in the expression of NF- $\kappa \mathrm{B}$ p 65 , the known inhibitor of collagen gene expression [25], compared to control cells (Fig. 4g). Opposite phenomenon was observed after 48 h incubation with OXY. An increase in the expression of NF- $\kappa \mathrm{B}$ p65 can explain only slight increase in collagen biosynthesis due to OXY action at this time (Fig. 1b).
In view of this data, it seems that OXY-dependent increase in collagen biosynthesis may be a consequence of increase in prolidase activity and the enzyme protein level, increase in pAkt level, and inhibition of pERK1/2 and NF$\kappa \mathrm{B}$ p65.

\section{Discussion}

Skin fibroblasts are connective tissue cells specialized in collagen biosynthesis. For this reason, they are a good model for studies of the effects of regulatory factors on collagen metabolism. Furthermore, fibroblasts would undergo aerobic glycolysis providing increased pyruvate/lactate that could then be used for the mitochondrial TCA cycle, oxidative phosphorylation, and ATP production for anabolic stimulation. 
Fig. 4 Western blot analysis for $\alpha_{2}$-integrin (a), $\beta_{1}$-integrin (b) receptor subunits, IGF-I receptor $(\mathbf{c}), \mathrm{pERK} 1 / 2(\mathbf{d})$, ERK1/2 (e), pAkt (f), and NF$\kappa \mathrm{B}$ p $65(\mathrm{~g})$ in control human skin fibroblasts and cultured for 24 and $48 \mathrm{~h}$ in the medium containing different concentrations of OXY. The mean values of six pooled cell homogenate extracts from six separate experiments are presented. The intensity of the bands was quantified by densitometric analysis.

Densitometry was done with BioSpectrum Imaging System and presented as arbitrary units b. The same amount of supernatant protein $(20 \mu \mathrm{g})$ was run in each lane. The expression of $\beta$-actin served as a control for protein loading (h) a

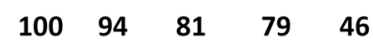

$150 \mathrm{kDa}$

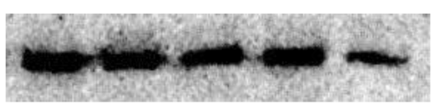

b

$130 \mathrm{kDa}$

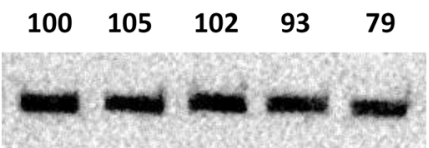

C

$130 \mathrm{kDa}$ $\begin{array}{lllll}100 & 91 & 87 & 87 & 76\end{array}$

$95 \mathrm{kDa}$

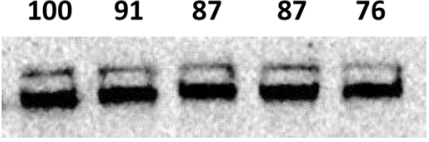

d

$44 \mathrm{kDa}$

$42 \mathrm{kDa}$

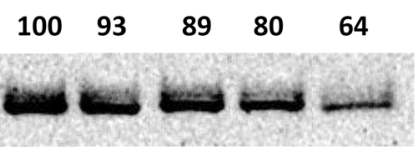

e

$\begin{array}{lllll}100 & 107 & 110 & 111 & 114\end{array}$

$44 \mathrm{kDa}$

$42 \mathrm{kDa}$

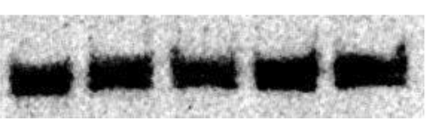

f

56 kDa

$\begin{array}{lllll}100 & 102 & 109 & 113 & 119\end{array}$

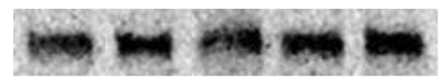

g

$\begin{array}{lllll}100 & 82 & 84 & 74 & 68\end{array}$

$65 \mathrm{kDa}$

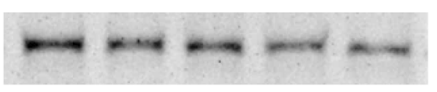

h

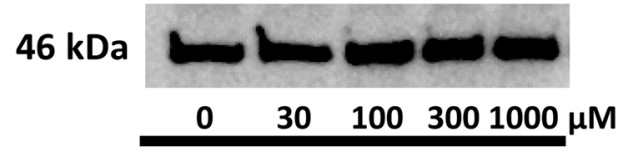

$24 \mathrm{~h}$

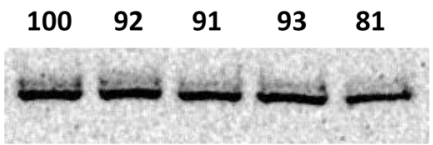

PERK $1 / 2$

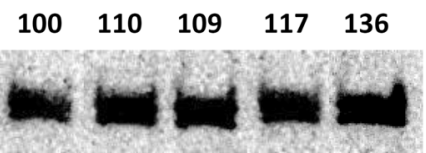

ERK 1/2

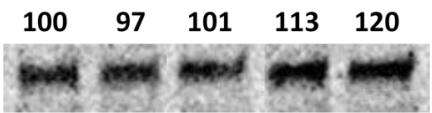

pAkt

a2-integrin

B1-integrin

IGF-IR

$\begin{array}{lllll}100 & 101 & 108 & 126 & 128\end{array}$

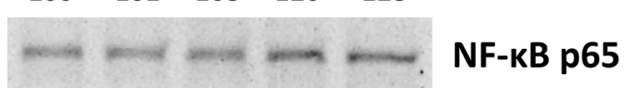

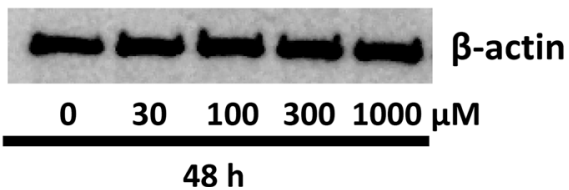

The data presented here show that OXY induces an increase in collagen biosynthesis in human skin fibroblasts. The increase in collagen biosynthesis was correlated with an increase in prolidase activity and the enzyme protein level. Our studies support the relationship between collagen synthesis and prolidase activity. A similar relationship was observed during the fibrotic process, where an increase in prolidase activity was accompanied by an increase in tissue collagen deposition [12]. The link between collagen production and prolidase activity was also found in cultured human skin fibroblasts treated with anti-inflammatory drugs [13], during experimental aging of these cells [14], fibroblasts chemotaxis [37] and cell surface integrin receptor ligation [17]. However, the link between OXYdependent accumulation of pyruvate and up-regulation of collagen biosynthesis is not fully understood. Previously, we proposed that the mechanism may originate at the level of interconversion of pyruvate/PEP.

Oxythiamine (OXY) affects pentose phosphate pathways [35] and by inhibition of pyruvate decarboxylase increases the amount of pyruvate [2]. Pyruvate is converted into PEP by PEPCK catalyzing phosphorylation and concomitant decarboxylation of oxaloacetate. This reaction is the first step of the gluconeogenic pathway, which is subject to regulation. PEP is known as a strong, competitive inhibitor of prolidase activity "in vitro" [20]. In our previous study, we found that PEP contributed to decrease in collagen biosynthesis in cultured human skin fibroblasts through depression of $\alpha_{2} \beta_{1}$ integrin and IGF-IR signaling. However, we suggest that there is no direct correlation 


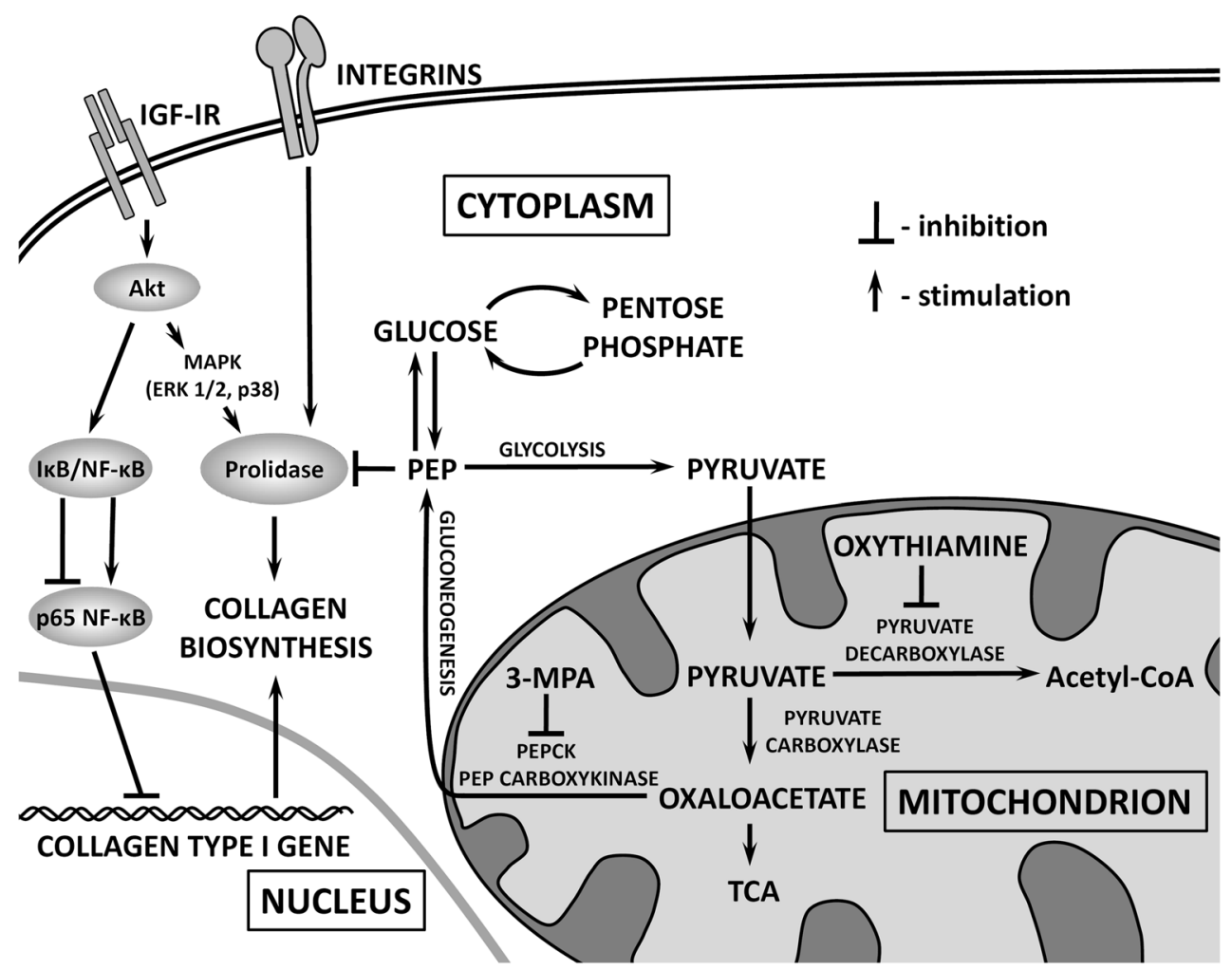

Fig. 5 Graphical abstract. In the experimental conditions (OXYtreated cells for $24 \mathrm{~h}$ ), there is up-regulation of AKT that contributes to stimulation of collagen biosynthesis through activation of prolidase-an enzyme supporting proline for collagen biosynthesis and down-regulation of NF-kB - transcription factor that inhibits collagen type I gene expression. During that time, OXY directs pyruvate for TCA cycle that eliminate gluconeogenesis and production of PEP-

between collagen biosynthesis and prolidase activity and level [19].

We investigated whether pyruvate or PEP is involved in OXY-dependent regulation of collagen biosynthesis. It is apparent from our study that inhibitor of PEPCK up-regulated prolidase activity in different experimental conditions. It suggests that decreased activity of PEPCK contributes to suppression of PEP production (competitive inhibitor of prolidase activity) [20] and is responsible for slight increase in the enzyme activity. In certain experimental conditions ( $6 \mathrm{~h}$ incubation), we found OXYdependent inhibition of prolidase activity resulted probably from PEP accumulation. The potential mechanism of OXY-dependent regulation of prolidase activity and collagen biosynthesis is outlined in Fig. 5.

Collagen is known as a ligand for $\alpha_{2} \beta_{1}$ integrin. Previously, it has been shown that $\beta_{1}$-integrin receptor is involved in signaling, which regulates collagen biosynthesis [38] and prolidase activity [17, 39]. Another important point of collagen biosynthesis regulation is at the level of insulin-like growth factor-I receptor (IGF-IR). inhibitor of prolidase activity. The net result is up-regulation of collagen biosynthesis. However, $48 \mathrm{~h}$ incubation of the cells with OXY may contribute to accumulation of oxaloacetate in mitochondria and stimulation of gluconeogenesis that increases cytoplasmic concentration of $\mathrm{PEP}$-inhibitor of prolidase and consequently collagen biosynthesis. This process may be augmented by inhibitory effect of OXY on pentose cycle

IGF-I is one of the most potent collagen-stimulating factors in collagen synthesizing cells [22]. Therefore, we considered $\beta_{1}$ integrin and IGF-IR as a potential target in OXYinduced increase of the above processes.

Our observations suggest that in fibroblasts OXY induces collagen biosynthesis independently of $\alpha_{2} \beta_{1}$ integrin receptor and IGF-IR expressions. Presumably, increase in prolidase activity and level in fibroblasts due to $\mathrm{OXY}$ action is a result of increase in ERK1/2 signaling and stimulation of Akt, suggesting that in experimental conditions ERK1/2 and Akt proteins represent signaling molecules that respond to OXY action.

Several other studies suggest that prolidase-dependent regulation of collagen biosynthesis may take place at the transcriptional level. The transfection of colorectal cancer cells with prolidase vector inhibited NF- $\mathrm{\kappa B}$ p65 expression [40], well-recognized inhibitor of expression of $\alpha 1$ and $\alpha 2$ subunits of type I collagen [25, 41, 42]. Another evidence for the role of prolidase in regulation of NF- $\mathrm{KB}$ expression provides experiment showing that inhibition of prolidase activity by Cbz-Pro contributed to up-regulation of NF- $\mathrm{KB}$ 
p65 expression in fibroblasts [40]. In fact, our data showed that OXY-dependent increase in prolidase activity (by about $57 \%$ of control) and collagen biosynthesis (by about $36 \%$ of control) is accompanied by decrease in the expression of NF- $\kappa \mathrm{B}$ p65, after $24 \mathrm{~h}$ incubation. During $48 \mathrm{~h}$ incubation of fibroblasts in medium, supplemented with OXY prolidase activity and collagen biosynthesis was not significantly increased (both by about $14 \%$ of control) and down-regulation of NF- $\kappa \mathrm{B}$ p 65 was not observed.

Although the link between up-regulation of AKT and down-regulation of ERK1/2 and NF- $\mathrm{KB}$ in OXY-treated cells is not known, it cannot be excluded that underlying mechanism may also involve pentose cycle. OXY is known as a transketolase inhibitor that may cause a severe deficiency in high-energy phosphate bonds, contributing to decrease in protein phosphorylation and cell cycle arrest [36].

It has been demonstrated in many in vitro studies that OXY inhibits cancer cell growth through suppression of the cell cycle. However, the molecular mechanism of the action is poorly understood. Some data suggested that in pancreatic cancer cells OXY may specifically induce cell cycle arrest through deactivation of the MAPK pathways, without effects on NF- $\kappa B$ [43]. Whether such a mechanism takes place in normal cells requires to be explored.

The data suggest that OXY may exert its effect on collagen biosynthesis through stimulation of prolidase activity and the enzyme protein level, pAkt level, and inhibition in pERK1/2 and NF- $\kappa B$ p65 transcriptional activity.

Open Access This article is distributed under the terms of the Creative Commons Attribution License which permits any use, distribution, and reproduction in any medium, provided the original author(s) and the source are credited.

\section{References}

1. Tylicki A, Siemieniuk M (2011) Thiamine and its derivatives in the regulation of cell metabolism. Postepy Hig Med Dosw 65:447-469

2. Tylicki A, Łempicka A, Romaniuk-Demonchaux K, Czerniecki J, Dobrzyń P, Strumiło S (2003) Effect of oxythiamin on growth rate, survival ability and pyruvate decarboxylase activity in Saccharomyces cerevisiae. J Basic Microbiol 43:522-529

3. Cerbón-Ambriz J, Cerbón J, González E, Rojkind M (1987) Lactate and pyruvate increase the incorporation of $[3 \mathrm{H}]$ proline into collagen $[3 \mathrm{H}]$ hydroxyproline in liver slices of $\mathrm{CCl} 4$ cirrhotic rats. Lab Invest 57:392-396

4. Tylicki A, Czerniecki J, Dobrzyn P, Matanowska A, Olechno A, Strumilo S (2005) Modification of thiamine pyrophosphate dependent enzyme activity by oxythiamine in Saccharomyces cerevisiae cells. Can J Microbiol 51:833-839

5. Myara I, Charpentier C, Lemonnier A (1984) Prolidase and prolidase deficiency. Life Sci 34(21):1985-1998

6. Chamson A, Voigtlander V, Myara I, Frey J (1989) Collagen biosynthetic anomalies in prolidase deficiency: effect of glycyl-
L-proline on the degradation of newly synthesized collagen. Clin Physiol Biochem 7:128-136

7. Mock WL, Green PC, Boyer KD (1990) Specificity and pH dependence for acylproline cleavage by prolidase. J Biol Chem 265:19600-19605

8. Yaron A, Naider F (1993) Proline-dependent structural and biological properties of peptides and proteins. Crit Rev Biochem Mol Biol 28:31-81

9. Emmerson KS, Phang JM (1993) Hydrolysis of proline dipeptides completely fulfills the proline requirement in a proline-auxotropic Chinese hamster ovary cell line. J Nutr 123:909-914

10. Jackson SH, Dennis AW, Greenberg M (1975) Iminopeptiduria: a genetic defect in recycling of collagen; a method for determining prolidase in erythrocytes. CMA J 113:759-763

11. Goodman SI, Solomons CC, Muschenheim F, Macintyre CA, Miles B, O'Brien D (1968) A syndrome resembling lathyrism associated with iminodipeptiduria. Am J Med 45:152-159

12. Myara I, Miech G, Fabre M, Mangeot M, Lemonnier A (1987) Changes in prolinase and prolidase activity during $\mathrm{CCl}_{4}$ administration inducing liver cytolysis and fibrosis in rat. $\mathrm{Br} \mathrm{J}$ Exp Pathol 68:7-13

13. Miltyk W, Karna E, Palka J (1996) Inhibition of prolidase activity by non-steroid antiinflammatory drugs in cultured human skin fibroblasts. Pol J Pharmacol 48:609-613

14. Palka J, Miltyk W, Karna E, Wołczyński S (1996) Modulation of prolidase activity during in vitro aging of human skin fibroblasts the role of extracellular matrix collagen. Tokai J Exp Clin Med $21: 207-213$

15. Muszynska A, Palka J, Gorodkiewicz E (2000) The mechanism of daunorubicin-induced inhibition of prolidase activity in human skin fibroblasts and its implication to impaired collagen biosynthesis. Exp Toxicol Pathol 52:149-155

16. Miltyk W, Palka JA (2000) Potential role of pyrroline 5-carboxylate in regulation of collagen biosynthesis in cultured human skin fibroblasts. Comp Biochem Physiol A 125:265-271

17. Palka JA, Phang JM (1997) Prolidase activity in fibroblasts is regulated by interaction of extracellular matrix with cell surface integrin receptors. J Cell Biochem 67:166-175

18. Palka JA, Phang JM (1998) Prolidase in human breast cancer MCF-7 cells. Cancer Lett 127:63-70

19. Karna E, Pałka JA (2008) Phosphoenolpyruvate-dependent inhibition of collagen biosynthesis, alpha2beta1 integrin and IGF-I receptor signaling in cultured fibroblasts. Mol Cell Biochem 315:61-67

20. Radzicka A, Wolfenden R (1991) Analogues of intermediates in the action of pig kidney prolidase. Biochemistry 30:4160-4164

21. Baserga R (2005) The insulin-like growth factor-I receptor as a target for cancer therapy. Expert Opin Ther Targets 9:753-768

22. Goldstein RH, Poliks CF, Pilch PF, Smith BD, Fine A (1989) Stimulation of collagen formation by insulin and insulin-like growth factor-I in cultures of human lung fibroblasts. Endocrinology 124:964-970

23. Tanaka H, Wakisaka A, Ogasa H, Kawai S, Liang CT (2002) Effect of IGF-I and PDGF administered in vivo on the expression of osteoblast-related genes in old rats. J Endocrinol 174:63-70

24. Miltyk W, Karna E, Wołczyński S, Pałka JA (1998) Insulin-like growth factor I-dependent regulation of prolidase activity in cultured human skin fibroblasts. Mol Cell Biochem 189:177-184

25. Kouba DJ, Chung KY, Nishiyama T, Vindevoghel L, Kon A, Klement JF, Uitto J, Mauviel A (1999) Nuclear factor-kappa B mediates TNF-alpha inhibitory effect on alpha 2(I) collagen (COL1A2) gene transcription in human dermal fibroblasts. J Immunol 162:4226-4234

26. Carmichael J, Degraff W, Gazdar A, Minna J, Mitchell J (1987) Evaluation of a tetrazolinum-based semiautomated colorimetric assay: assessment of chemosensitivity testing. Cancer Res 47:936-942 
27. Myara I, Charpentier C, Lemonnier A (1982) Optimal conditions for prolidase assay by proline colorimetric determination: application to imidopeptiduria. Clin Chim Acta 125:193-205

28. Lowry OH, Rosebrough NI, Farr AL, Randall IR (1951) Protein measurement with the Folin reagent. J Biol Chem 193:265-275

29. Oyamada I, Palka J, Schalk EM, Takeda K, Peterkofsky B (1990) Scorbutic and fasted guinea pig sera contain an insulin-like growth factor I reversible inhibitor of proteoglycan and collagen synthesis in chick embryo chondrocytes and adult human skin fibroblasts. Arch Biochem Biophys 276:85-93

30. Peterkofsky B, Chojkier M, Bateman J (1982) Determination of collagen synthesis in tissue and cell culture system. In: Fufthmar M (ed) Immunochemistry of the extracellular matrix. CRC Press, Boca Raton, pp 19-47

31. Laemmli UK (1970) Cleavage of structural proteins during the assembly of the head of bacteriophage T4. Nature 227:680-685

32. Myara I, Charpentier C, Gautier M, Lemonnier A (1985) Cell density affects prolidase and prolinase activity and intracellular amino acid levels in cultured human cells. Clin Chim Acta 150:1-9

33. Makela JK, Vuorio T, Vuorio E (1990) Growth-dependent modulation of type I collagen production and mRNA levels in cultured human skin fibroblasts. Biochim Biophys Acta 1049:171-176

34. Basu TK, Dickerson JW (1976) The thiamin status of early cancer patients with particular reference to those with breast and bronchial carcinomas. Oncology 33:250-252

35. Boros LG, Puigjaner J, Cascante M, Lee WN, Brandes JL, Bassilian S, Yusuf FI, Williams RD, Muscarella P, Melvin WS, Schirmer WJ (1997) Oxythiamine and dehydroepiandrosterone inhibit the nonoxidative synthesis of ribose and tumor cell proliferation. Cancer Res 57:4242-4248
36. Raïs B, Comin B, Puigjaner J, Brandes JL, Creppy E, Saboureau D, Ennamany R, Lee WP, Boros LG, Cascante M (1999) Oxythiamine and dehydroepiandrosterone induce a G1 phase cycle arrest in Ehrlich's tumor cells through inhibition of the pentose cycle. FEBS Lett 456:113-118

37. Palka JA, Karna E, Miltyk W (1997) Fibroblast chemotaxis and prolidase activity modulation by insulin-like growth factor II and mannose 6-phosphate. Mol Cell Biochem 168:177-183

38. Ivaska J, Reunanen H, Westermarck J, Koivisto L, Kahari VM, Heino J (1999) Integrin alpha2beta1 mediates isoform-specific activation of $\mathrm{p} 38$ and up-regulation of collagen gene transcription by a mechanism involving the alpha2 cytoplasmic tail. J Cell Biol 147:401-416

39. Palka JA, Phang JM (1994) Prolidase (PLD) activity in regulated by cell surface-extracellular matrix (ECM) interaction in normal fibroblast and MCF-7 cells. Proc Am Ass Cancer Res 35:531

40. Surazynski A, Miltyk W, Palka J, Phang JM (2008) Prolidasedependent regulation of collagen biosynthesis. Amino Acids 35:731-738

41. Rippe RA, Schrum LW, Stefanovic B, Solís-Herruzo JA, Brenner DA (1999) NF-kappaB inhibits expression of the alpha1(I) collagen gene. DNA Cell Biol 18:751-761

42. Miltyk W, Karna E, Palka JA (2007) Prolidase-independent mechanism of camptothecin-induced inhibition of collagen biosynthesis in cultured human skin fibroblasts. J Biochem 141:287-292

43. Zhang H, Cao R, Lee WN, Deng C, Zhao Y, Lappe J, Recker R, Yen Y, Wang Q, Tsai MY, Go VL, Xiao GG (2010) Inhibition of protein phosphorylation in MIA pancreatic cancer cells: confluence of metabolic and signaling pathways. J Proteome Res 9:980-989 